\title{
ANALISIS PELAKSANAAN PRAKTIKUM PADA MATA PELAJARAN BIOLOGI DI SMA NEGERI 1 TEBING TINGGI
}

\author{
Dea Chika Anjani Kimura, Idramsa \\ Program Studi Pendidikan Biologi, FMIPA, Universitas Negeri Medan, Medan \\ Jl. Willem Iskandar Psr. V Medan Estate, Medan, Indonesia, 20221 \\ *Korespondensi Author: gloriasirait23@gmail.com
}

\section{INFO ARTIKEL}

Histori Artikel

Received 11 Juli 2018

Revised 5 Maret 2020

Accepted 10 Maret 2020

Published 17 Maret 2020

Keywords:

Praktikum Biologi, Laboratorium Biologi, Kendala Praktikum

\begin{abstract}
ABSTRAK
Penelitian ini bertujuan untuk mengetahui pelaksanaan praktikum biologi, keadaan laboratorium, dan kendala yang dialami pada pelaksanaan kegiatan praktikum Biologi di SMA Negeri 1 Tebing Tinggi pada Semester Genap T.P 2017/2018. Sampel yang digunakan adalah kelas X MIA dan XI MIA yang berjumlah 143 siswa, dan 2 orang guru yang diambil secara random sampling. Penelitian ini menggunakan metode deskriptif. Data yang diperlukan diperoleh melalui angket, observasi dan wawancara. Hasil penelitian menunjukkan bahwa minat siswa terhadap praktikum yang sangat baik (89\%), keadaan laboratorium tergolong baik (78\%), waktu praktikum yang tergolong baik (64\%), persiapan dan pelaksanaan praktikum baik (76\%), laporan dan evaluasi praktikum tergolong baik (73\%), dan kesehatan dan keselamatan kerja sangat baik (92\%). Sedangkan frekuensi pelaksanaan praktikum biologi masih tergolong kurang baik dengan persentase $50 \%$ untuk kelas X dan $60 \%$ untuk kelas XI. Adapun sarana laboratorium biologi yang diperlukan sudah tersedia dengan sebagian besar dalam kondisi yang baik. Kendala dalam pelaksanaan praktikum adalah kurangnya inisiatif guru dalam pemanfaatan sarana laboratorium yang telah ada dan banyak mikroskop yang ditemukan tidak dalam kondisi yang baik (berjamur).
\end{abstract}

\begin{abstract}
ABSTRAK
This study aims to determine the implementation of biology practicum, laboratory conditions, and the constraints experienced in the implementation of Biology practicum activities in Tebing Tinggi 1 High School in Even Semester T.P 2017/2018. The sample used was class X MIA and XI $\mathrm{MIA}$, amounting to 143 students, and 2 teachers were taken by random sampling. This research uses a descriptive method. The data needed is obtained through questionnaires, observations, and interviews. The results showed that students' interest in practicum was very good (89\%), laboratory conditions were classified as good (78\%), practicum time was good (64\%), preparation and implementation of practicum was good (76\%), practicum reports and evaluations were classified as good (73\%), and occupational health and safety are very good (92\%). While the frequency of biology practicum is still not good with a percentage of $50 \%$ for class $X$ and $60 \%$ for class XI. The required biological laboratory facilities are already available with most in good condition. The obstacle in practicum implementation is the lack of teacher initiative in the use of existing laboratory facilities and many microscopes found not in good condition (moldy).
\end{abstract}

Copyright (C) 2019 Universitas Negeri Medan. Artikel Open Access dibawah lisensi CCBY-4.0 (https://creativecommons.org/licenses/by/4.0)

\section{How To Cite:}

Kimura, D.C.A., \& Idramsa. (2019). Analisis Pelaksanaan Praktikum Pada Mata Pelajaran Biologi Di SMA Negeri 1 Tebing Tinggi. Jurnal Pelita Pendidikan, 7(4), 197-204. 


\section{PENDAHULUAN}

Biologi merupakan salah satu ilmu yang memiliki arti penting bagi pendidikan di sekolah. Biologi berkaitan dengan cara mencari tahu tentang alam secara sistematis, sehingga biologi bukan hanya penguasaan tentang kumpulan pengetahuan yang berupa fakta-fakta, konsep-konsep, atau prinsip-prinsip saja tetapi juga merupakan suatu proses penemuan. Oleh karena itu pembelajaran biologi harus ditekankan pada pengalaman langsung untuk mengembangkan kompetensi agar siswa mampu menjelajahi alam sekitar secara alamiah. Mempelajari biologi menjadi kurang optimal apabila tidak ditunjang dengan pengalaman nyata kepada siswa, salah satunya dengan praktikum (Mastika et al 2014).

Pada kurikulum 2013 peserta didik diarahkan pada pendekatan sikap, pengetahuan dan keterampilan. Salah satu hal penting dari kurikulum 2013 dalam meningkatkan mutu pembelajaran yakni pendekatan keterampilan dengan adanya pelaksanaan praktikum (Nazila, 2017).

Menurut Ariyati (2010) pembelajaran berbasis praktikum menjadi alternatif pembelajaran yang baik bagi peserta didik untuk mengembangkan keterampilan, kemampuan berpikir (hands-on dan minds-on) karena peserta didik dituntut untuk aktif dalam memecahkan masalah, berpikir kritis dan kreatif dalam menganalisis dana mengaplikasikan konsep, dan prinsip-prinsip agar menjadi lebih bermakna.

Keberhasilan dalam pembelajaran khususnya dalam pelaksanaan kegiatan praktikum didukung oleh beberapa faktor, yaitu faktor guru, penguasaan materi dan penguasaan metode teknik mengajar oleh guru, dan penguasaan mengelola kegiatan praktikum. Faktor lainnya yaitu kelengkapan sarana dan prasarana belajar yang mendukung dalam kegiatan praktikum. Sarana prasarana dapat menjadi faktor pendukung atau faktor penghambat pembelajaran sebagian tergantung dari bagaimana guru mengupayakannya dan menyikapinya (Rezeqi dan Hasruddin, 2012).

Pelaksanaan praktikum tidak terlaksana dengan baik dikarenakan beberapa faktor. Seperti penelitian yang dilakukan oleh Nasution dan Hasairin (2016) menunjukkan beberapa kendala dialami seperti tidak tersedianya penuntun praktikum biologi, lembar kerja praktikum masih sangat terbatas, ketiadaan jadwal praktikum yang tetap, keterbatasan waktu pembelajaran yang ada, dan praktikum kurang diberdayakan di lapangan, karena banyak guru yang melakukan praktikum dianggap menyita waktu dan tenaga. Hal tersebut dapat mengakibatkan pelaksanaan praktikum yang kurang maksimal.

Berdasarkan hasil observasi awal yang dilakukan dan wawancara dengan salah satu guru bidang studi, memperlihatkan bahwa kegiatan praktikum masih dilakukan tetapi jadwal kegiatan praktikum belum dilaksanakan secara maksimal, buku penuntun praktikum dan lembar kerja masih sangat terbatas dan tergantung kepada guru atau buku pegangan siswa. Adapun sebagian guru yang masih kesulitan untuk menyesuaikan ataupun melaksanakan kegiatan praktikum. SMA Negeri 1 Tebing Tinggi sudah menggunakan kurikulum 2013 dimana alah satu hal penting dari kurikulum 2013 dalam meningkatkan mutu pembelajaranyakni pendekatan keterampilan dengan adanya pelaksanaan praktikum. Oleh karena itu, penelitian ini bertujuan untuk mengetahui bagaimana pelaksanaan praktikum di SMA Negeri 1 Tebing Tinggi.

\section{METODE PENELITIAN}

Penelitian ini telah dilakukan di SMA Negeri 1 Tebing Tinggi yang berlokasi di Jl. Kom. Laut Yos Sudarso Kecamatan Rambutan Kota Tebing Tinggi, Sumatera Utara. Penelitian dilakukan pada bulan April-Juni 2018.Populasi pada penelitian ini adalah seluruh siswa kelas X MIA dan XI MIA SMA Negeri 1 Tebing Tinggi tahun pembelajaran 2017/2018 yang berjumlah 16kelas yakni sebanyak 571 siswa dan seluruh guru biologi SMA Negeri 1 Tebing Tinggi yang berjumlah 5 orang. Peneliti mengambil sampel 4 kelas dari kelas X MIA dan XI MIA yang berjumlah 143 siswa, dan guru biologi sebanyak 2 orang dengan teknik random samplingdimana setiap unsur dari keseluruhan populasi mempunyai kesempatan atau peluang yang sama untuk menjadi sampel penelitian.

Jenis Penelitian ini adalah penelitian deskriptif kuantitatif yang menggunakan metode survey yaitu menggambarkan dan menjelaskan data berdasarkan apa adanya kenyataan di lapangan.. Penelitian ini mengunakan instrumen 
pengumpul data untuk mendapatkan jawaban permasalahan dan pencapaian tujuan Penelitian.

Teknik pengumpulan data pada penelitian

ini menggunakan beberapa instrumen yaitu:

1. Angket, yang digunakan adalah angket tertutup dengan menggunakan skala ordinal yang diberikan kepada siswa dan guru.

2. Wawancara dilakukan kepada guru biologi dengan tujuan untuk melengkapi penjelasan observasi dan angket. Jenis wawancara yang dilakukan yaitu wawancara terbuka.

3. Lembar observasi digunakan untuk mengamati frekuensi pelaksanaan praktikum dan kondisi laboratorium biologi, Ketersedian perlangkapan, alat dan bahan yang diperlukan dilihat dari jumlah dan keadaannya untuk menunjang kegiatan praktikum pada semester genap.

4. Dokumentasi, Dokumen merupakan fakta dan data tersimpan dalam berbagai bahan yang terbentuk dokumentas.

Tahapan pada penelitian meliputi 3 tahapan yakni tahap persiapan, tahap pelaksanaan dan tahap pengolahan data.

Tahap persiapan penelitian meliputi: mengurus surat izin observasi dan melakukan observasi awal ke sekolah. Peneliti mengidentifikasi permasalahan yang terjadi. Kemudian menyususn proposal penelitian dan instrumen penelitian. Instrumen penelitian berupa angket, wawancara, dan lembar observasi yang akan
divalidasikan.Tahap pelaksanaan penelitan meliputi: Memberikan angket kepada siswa, melakukan wawancara dengan guru biologi mengenai pelaksanaan kegiatan praktikum dan kendala pelaksanaan kegiatan praktikum, dan melengkapi lembar observasi mengenai frekuensi pelaksanaan kegiatan praktikum dan keadaan laboratorium biologi di sekolah.Pada tahap akhir yang dilakukan diantaranya: data yang telah dikumpulkan akan diolah dengan menggunakan rumus (teknik analisis data) sehingga didapatkan hasil secara kuantitatif pelaksanaan praktikum di SMA Negeri 1 Tebing Tinggi. Kemudian mendeskripsikan hasil dari penelitian yang telah dilakukan.

Teknik analisis data angketdigunakan dalam penelitian ini adalah teknik analisisdeskriptif dengan perhitungan persentase yangdiperoleh dengan memakai rumus:

$$
\mathrm{NP}=\frac{\text { skor riil }}{\text { skor ideal }} \times 100 \%
$$

(Sugiyono, 2017).

Keterangan:

$\mathrm{N}$

skor riil

skor ideal
$=$ Nilai persentase

= jumlah skor yang diperoleh

=jumlah responden (skormax)
Klasifikasi skor selanjutnya diubah menjadi klasifikasi dalam bentuk persentase, kemudian ditafsirkan kedalam bentuk kalimat yang bersifat kualitatif. Kriteria persentase penilaian dapat dilihat pada Tabel 1.

Tabel 1. Kriteria Persentase

\begin{tabular}{ccc}
\hline No & Rentang Nilai & Kriteria \\
\hline 1 & $81 \%-100 \%$ & Sangat baik \\
\hline 2 & $61 \%-80 \%$ & Baik \\
\hline 3 & $41 \%-60 \%$ & Kurang Baik \\
\hline 4 & $\leq 40 \%$ & Tidak Baik
\end{tabular}

\section{HASIL DAN PEMBAHASAN}

\section{Persepsi Pelaksanaan Kegiatan Praktikum}

Dari hasil data angket menunjukkan bahwa minat siswa di SMA Negeri 1 Tebing Tinggi terhadap pelaksanaan kegiatan praktikum adalah $89 \%$ yang termasuk dalam kategori yang sangat baik. Dari data angket menunjukkan keadaan laboratorium tergolong dalam kriteria baik dengan persentase 78\%, dan waktu praktikum menunjukkan persentase $64 \%$ yang juga termasuk dalam kriteria baik, adapun dalam persiapan dan pelaksanaan praktikum tergolong dalam kriteria yang baik dengan persentase $76 \%$, dan laporan dan evaluasi praktikum mencapai $73 \%$ yang juga termasuk dalam kriteria baik.

Dari hasil analisis data mengenai kesehatan dan keselamatan kerja pada saat praktikum di SMA Negeri 1 Tebing Tinggi menurut persepsi guru 
menunjukkan persentase $92 \%$ yang termasuk dalam kriteria yang sangat baik. Hasil data mengenai persepsi pelaksanaan praktikum dapat dilihat pada Gambar 1.

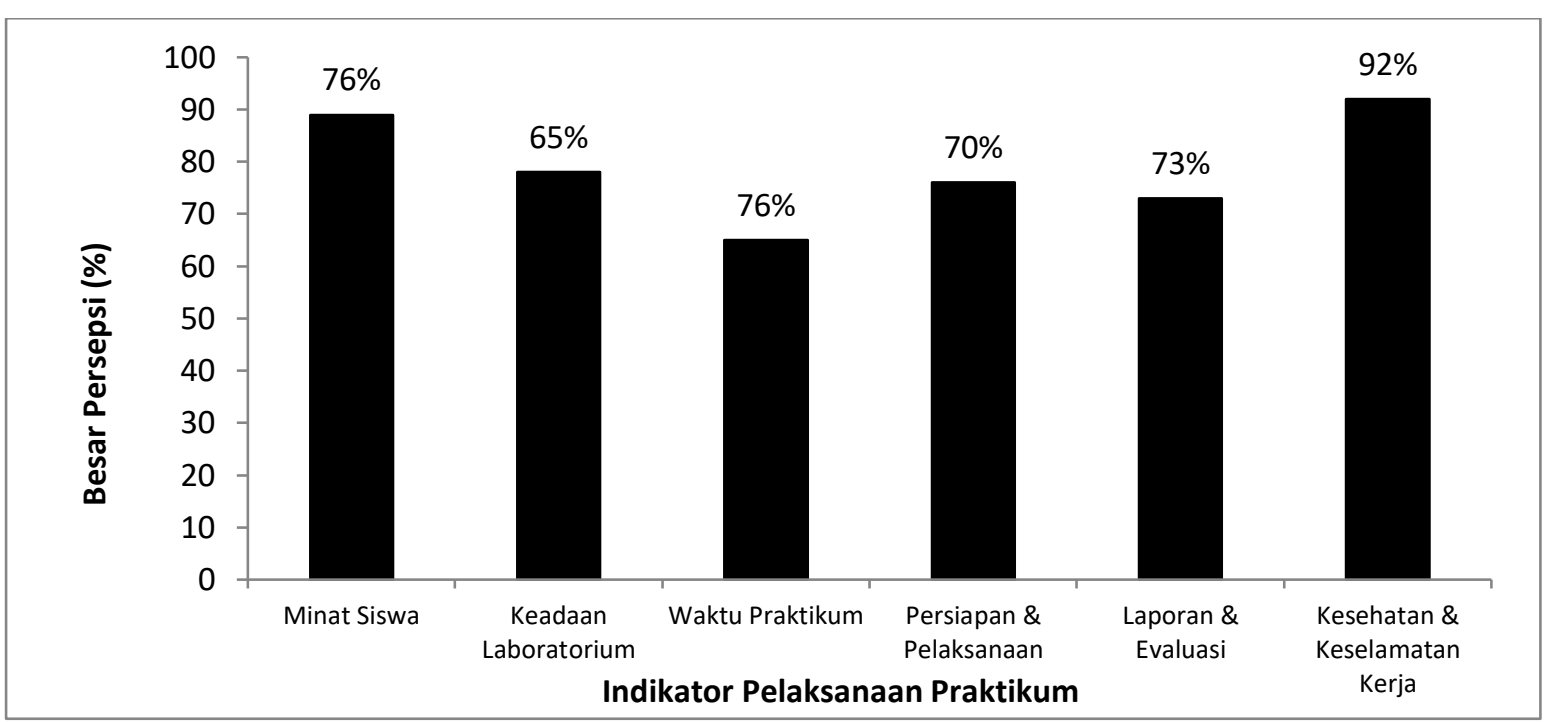

Gambar 1. Persepsi Pelaksanaan Praktikum Biologi

\section{Frekuensi Pelaksanaan Praktikum Biologi}

Jumlah kegiatan praktikum biologi SMA kelas $X$ selama semester genap adalah sebanyak 10 kali praktikum. Secara umum, frekuensi pelaksanaan praktikum biologi kelas $X$ di SMA Negeri 1 Tebing Tinggi adalah $50 \%$ ( 5 kali praktikum), yang termasuk kedalam kategori kurang baik.

Jumlah kegiatan praktikum biologi SMA kelas XI selama semester genap adalah sebanyak 10 kali praktikum. Secara umum, frekuensi pelaksanaan praktikum biologi kelas XI di SMA Negeri 1 Tebing Tinggi adalah $60 \%$ ( 6 kali praktikum), yang termasuk kedalam kategori kurang baik.

Sehingga secara umum frekuensi pelaksanaan kegiatan praktikum biologi SMA Negeri 1 Tebing Tinggi selama semester genap masih tergolong dalam kategoriu yang kurang baik. Frekuensi pelaksanaan kegiatan praktikum biologi selama semester genap dapat dilihat pada Gambar 2.

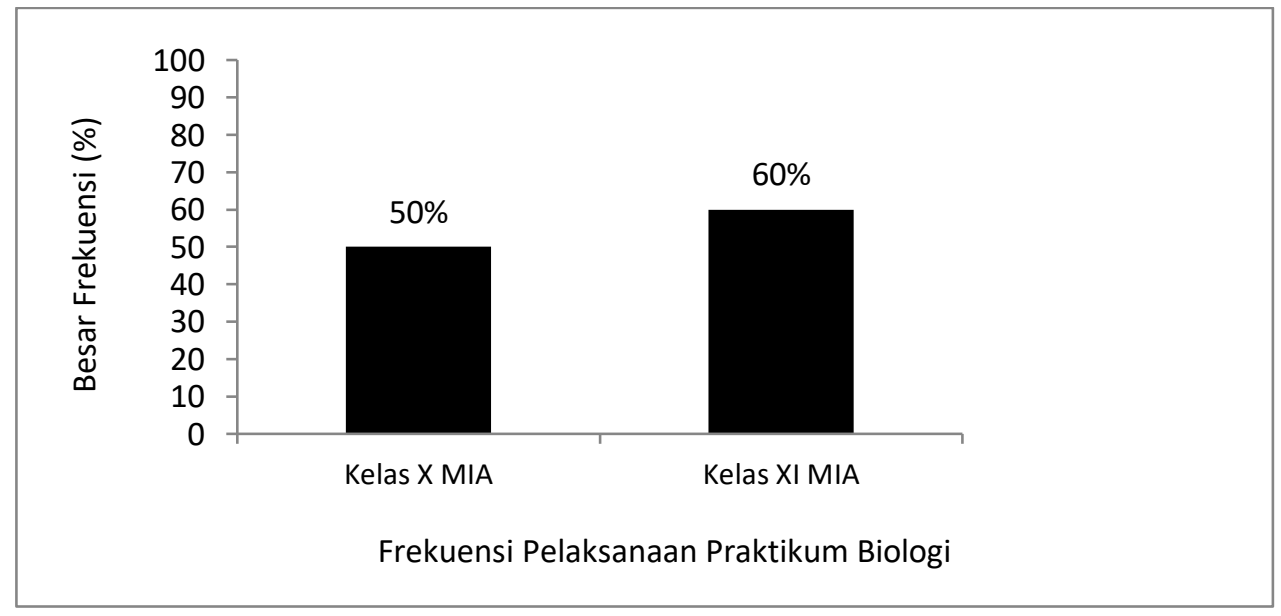

Gambar 2. Frekuensi Pelaksanaan Praktikum Biologi 


\section{Kelengkapan dan Kondisi Sarana Laboratorium}

Berdasarkan hasil observasi yang telah dilakukan terhadap kelengkapan dan kondisi laboratorium yang sesuai standar Permendiknas No. 24 Tahun 2007 di SMA Negeri 1 Tebing Tinggi menujukkan bahwa semua sarana yang diperlukan telah tersedia di laboratorium SMA Negeri 1 Tebing Tinggi dan sebagian besar dalam kondisi yang baik atau dapat digunakan, kecuali pada mikroskop dan bak cuci.

\section{Minat Siswa terhadap Kegiatan Laboratorium}

Kegiatan Laboratorium (Praktikum) dapat membangkitkan motivasi belajar sains. Melalui kegiatan laboratorium, siswa diberi kesempatan untuk memenuhi dorongan rasa ingin tahu dan ingin bisa. Prinsip ini akan menunjang kegiatan praktikum dimana siswa menemukan pengetahuan melalui eksplorasinya (Lubis dan Rizkika, 2017). Menurut Tuysuz (2010) melalui aktifitas laboratorium dapat meningkatkan ketertarikan peserta didik terhadap materi pelajaran dan membantu pembelajaran peserta didik.

Secara umum minat siswa terhadap kegiatan laboratorium di SMA Negeri 1 Tebing Tinggi sangat baik $(89,5 \%)$ yaitu pada kelas $X$, minat siswa mencapai $87 \%$ dan minat siswa pada kelas XI mencapai 90\%. Hal tersebut menunjukkan bahwa siswa di SMA Negeri 1 Tebing Tinggi antusias dan tertarik untuk melaksanakan kegiatan praktikum di dalam pembelajaran Biologi.

\section{Keadaan Laboratorium Biologi}

Keberadaan laboratorium di sekolah sangat penting dalam menunjang kegiatan belajar mengajar biologi, karena ada beberapa materi yang dalam memahaminya perlu melakukan pengamatan atau percobaan di laboratorium. Selain itu, dalam Peraturan Pemerintah Nomor 32 Tahun 2013 dijelaskan bahwa setiap satuan pendidikan wajib memiliki prasarana yang dapat menunjang proses pembelajaran yang teratur dan berkelanjutan salah satunya yaitu ruang laboratorium. Keberadaan laboratorium sangat penting dalam mendukung keberhasilan pembelajaran Biologi agar pemahaman peserta didik terhadap materi menjadi utuh dan komprehensif (Hamidah et al 2013).
Dari hasil analisis data yang diperoleh menunjukkan bahwa keadaan laboratorium biologi di SMA Negeri 1 Tebing Tinggi tergolong baik (78\%). SMA Negeri 1 telah memiliki laboratorium biologi tersendiri, yang dilengkapi ruang utama/ruang praktik, ruang persiapan dan ruang penyimpanan alat dan bahan. Hal yang serupa juga dikatakan oleh Rahman dalam Susilawati (2018) dalam penelitiannya yang mengatakan bahwa laboratorium seharusnya dibagi menjadi tiga bagian yaitu bagian utama digunakan untuk kegiatan praktikum, bagian kedua digunakan sebagai ruang persiapan dan bagian ketiga digunakan sebagai ruang penyimpanan alat dan bahan laboratorium. Ketersediaan alat dan bahan pada laboratorium biologi sudah sangat lengkap berdasarkan hasil observasi dan buku inventaris yang ada.

\section{Waktu Pelaksanaan Praktikum}

Dalam proses belajar mengajar secara formal waktu merupakan faktor pembatas utama, oleh karena itu harus dipertimbangkan secara cermat. Maka dalam pelaksanaan praktikum, waktu juga merupakan faktor yang cukup berpengaruh dan perlu diperhatikan. Kurikulum tidak memberikan waktu tersendiri untuk kegiatan praktikum. Sehingga guru dituntut untuk dapat membagi waktu antara teori dengan praktikum (Lubis dan Rizkika, 2017).

Berdasarkan hasil analisis data yang diperoleh menunjukkan bahwa waktu pelaksanaan praktikum biologi di SMA Negeri 1 tergolong dalam kategori baik (64\%). Berdasarkan hasil wawancara pada responden (guru dan laboran) pelaksanaan praktikum Biologi sudah memiliki penjadwalan tersendiri yaitu dilakukan diluar jam pelajaran atau di sore hari. Sehingga, laboratorium dapat digunakan oleh semua kelas yang membutuhkan tempat guna melaksanakan kegiatan praktikum. Lama waktu praktikum yang disediakan adalah 4590 menit.

\section{Persiapan dan Pelaksanaan Praktikum}

Persiapan dan pelaksanaan praktikum dalam suatu kegiatan praktikum sangatlah penting, karena dengan adanya persiapan dan pelaksanaan praktikum akan mendukung keberhasilan kegiatan praktikum yang maksimal. Dalam hal ini, guru sangat berperan dalam menyiapkan alat dan bahan 
sebelum pelaksanaan praktikum. Sebelum praktikum terlebih dahulu guru membagi siswa menjadi beberapa kelompok, memberikan penjelasan tentang kegiatan yang akan dilaksanakan dan menyampaikan tujuan dari setiap praktikum yang akan dilaksanakan (Lubis dan Rizkika, 2017).

Dari hasil analisis data, secara umum persiapan dan pelaksanaan praktikum biologi tergolong baik dengan persentase 76\%.Pada umumnya persiapan dan pelaksanaan praktikum di sekolah, guru dibantu oleh laboran. Seperti saat menyiapkan alat dan bahan, guru meminta bantuan aboran untuk menyiapkan alat dan bahan yang diperlukan sebelum siswa masuk kedalam laboratorium. Dan sebelum memulai kegiatan praktikum guru memberikan penjelasan dan tujuan dari kegiatan praktikum yang akan dilaksanakan. Selama praktikum berlangsung guru selalu mengawasi dan membimbing siswa. Peran guru terutama berkaitan dengan pengalaman mereka membantu siswa mengembangkan keterampilan proses sains.

\section{Laporan dan Evaluasi Praktikum}

Berdasarkan hasil analisis data secara umum laporan dan evaluasi praktikum biologi di SMA Negeri 1 Tebing Tinggi termasuk dalam kriteria yang baik (74\%).Berdasarkan hasil wawancara dengan guru bahwa setelah pelaksanaan praktikum siswa selalu ditugaskan membuat laporan praktikum. Adapun laporan praktikum yang disusun siswa dalam bentuk makalah atau pada double folio.

\section{Kesehatan dan Keselamatan Kerja}

Keselamatan kerja di dalam laboratorium merupakan salah satu unsur terpenting dalam pengelolaan laboratorium. Laboratorium yang dikelola secara baik merupakan tempat bekerja yang aman.Dan umumnya laboran atau guru yang bertugas untuk menyiapkan bahan atau zat tersebut ketika akan digunakan pada saat kegiatan praktikum. Adapun keselamatan kerja saat melakukan praktikum cukup diperhatikan, seperti siswa harus mengenakan jas lab saat melaksanakan kegiatan praktikum dan siswa diwajibkan memakai masker atau sarung tangan saat melakukan percobaan yang menggunakan bahan kimia dengan bimbingan dan pengawasan guru, kemudian laboratorium biologi di SMA Negeri 1 Tebing Tinggi juga dilengkapi sarana berupa alat pemadam api/kebakaran dan alat P3K. Dari hasil analisis data mengenai kesehatan dan keselamatan kerja pada saat praktikum di SMA Negeri 1 Tebing Tinggi menurut persepsi guru menunjukkan persentase $92 \%$ yang termasuk dalam kriteria yang sangat baik.

\section{Frekuensi Pelaksanaan Praktikum Biologi}

Berdasarkan hasil data menunjukkan bahwa frekuensi pelaksanaan praktikum biologi pada semester genap di SMA Negeri 1 Tebing Tinggi baik kelas $X$ dan kelas $X I$ masih tergolong dalam kategori yang kurang baik. Hal ini disebabkan karena guru yang bersangkutan masih merasa kesulitan untuk menyesuaikan waktu dalam melaksanakan kegiatan praktikum.

Adapun inisiatif guru untuk tetap melakukan kegiatan praktikum apabila jadwal yang telah ditentukan tidak dapat terlaksana yaitu dengan melakukan kegiatan praktikum di kelas pada pokok bahasan yang memungkinkan untuk melakukakannya di kelas.

Pada kegiatan praktikum kelas $X$, pemanfaatan alam juga dapat dilakukan pada pokok bahasan ekologi mengenai pengamatan komponen abiotik dan biotik serta mendiskusikannya di dalam kelas, dan pokok bahasan tumbuhan (plantae) pada kegiatan pengamatan tumbuhan biji (spermatophyta), Dan pada pokok bahasan perubahan linkungan dengan kegiatan praktikum berupa pembuatan produk daur ulang (pembuatan pupuk kompos) dilakukan dengan cara penugasan dirumah oleh guru.

Pada praktikum pengamatan morfologi khamir dan kapang, pengamatan bryophyta dan pteridophyta tidak dilakukan dan guru mengambil inisiatif bahwa materi tersebut dapat ditampilkan pada powerpoint sehingga tujuan pembelajaran tercapai. Praktikum pengamatan morfologi dan anatomi hewan vertebrata dan precobaan polusi air tidak terlaksana karena waktu yang diperlukan cukup banyak dan membutuhkan air yang cukup banyak, sedangkan persediaan air di dalam laboratorium tidak baik.

Pada kegiatan praktikum uji zat makanan pada pokok bahasan sistem pencernaan, kegiatan praktikum wajib dilakukan di laboratorium. Hal ini 
dikarenakan banyak bahan-bahan dan alat-alat yang diperlukan untuk digunakan pada saat praktikum. Dan pada pokok bahasan sistem regulasi, kegitan praktikum dilaksanakan dalam satu pertemuan. Kegiatan yang dilaksanakan antara lain uji indra perasa (kulit), uji indra pengecap, dan uji gerak refleks, sedangkan uji bintik buta tidak dilaksanakan. Hal ini merupakan inisiatif guru untuk dapat menggunakan waktu yang tersedia seoptimal mungkin.

Tidak terlaksananya praktikum percobaan proses pencernaan dimulut dikarenakan guru menganggap kegiatan praktikum uji zat makanan sudah memenuhi pembelajaran pada materi sistem pencernaan. Pada kegiatan praktikum menghitung volume udara pernapasan pada hewan dan uji kandungan urin tidak terlaksanan karena kurangnya inisiatif guru untuk melaksanakan praktikum tersebut dan menganggap waktu yang diperlukan cukup banyak.

Menurut Siburian et al (2017) praktikum memberi peluang kepada siswa untuk memperdalam pemahamannya terhadap materi ajar yang akan diperoleh melalui kegiatan belajar mengajar di kelas dan akan memberikan landasan baru bagi siswa untuk lebih kreatif dalam melakukan praktikum.

\section{Kelengkapan dan Kondisi Sarana Laboratorium}

Laboratorium yang baik harus dilengkapi dengan berbagai fasilitas untuk memudahkan pemakai laboratorium dalam melakukan aktivitasnya. Fasilitas tersebut ada yang berupa fasilitas umum (utilities) dan fasilitas khusus.Fasilitas umum merupakan fasilitas yang dapat digunakan oleh semua pemakai laboratorium contohnya penerangan, ventilasi, air, bak cuci (sinks), aliran listrik, dan gas. Fasilitas khusus berupa peralatan dan mebelair, contohnya meja siswa/mahasiswa, meja guru/dosen, kursi, papan tulis, lemari alat, lemari bahan, dan ruang timbang, lemari asam, perlengkapan P3K, pemadam kebakaran dan lain -lain (Susilawati, 2018). Berdasarkan hasil observasi, laboratorium biologi di SMA Negeri 1 Tebing Tinggi sudah memenuhi standar kelengkapan sarana laboratorium menurut Permendiknas No.24 Tahun 2007.

Laboratorium terdiri dari ruang persiapan, ruang penyimpanan alat dan bahan, dan juga ruang utama (ruang praktik) yang luasnya mencukupi siswa untuk leluasa melakukan kegiatan praktikum, yang rata-rata jumlah siswa tiap kelasnya adalah 35 siswa. Terdapat memiliki 6 buah bak cuci di dalam laboratorium, namun tidak dapat digunakan dengan baik (kondisi kurang baik).Adapun perlengkapan, alat dan bahan yang diperlukan untuk menunjang praktikum selama semester genap terdiri dari berbagai jenis diantaranya perabot, peralatan pendidikan, media pendidikan, bahan habis pakai dan perlengkapan lainnya telah tersedia. Tetapi terdapat alat yang tidak dapat digunakan atau tidak dalam kondisi yang baik. Seperti pada mikroskop yang ada (mikroskop cahaya) yang berjumlah 25 buah tetapi hanya 7 mikroskop yang dalam kondisi baik, sedangkan selebihnya terdapat jamur pada lensanya dan beberapa mikroskop rusak (tidak dapat digunakan sama sekali).

\section{Kendala dalam Melaksanakan Kegiatan Praktikum}

Berdasarkan hasil observasi menunjukkan data frekuensi pelaksanaan kegiatan praktikum masih tergolong kurang baik. Salah satu faktornya yaitu peranan guru dalam pembelajaran biologi belum dapat memenuhi prinsip-prinsip pembelajaran biologi yang diharapkan, seperti belum optimalnya pemanfaatan laboratorium yang telah menyediakan semua alat yang diperlukan.

Adapun pada peralatan ditemukan bahwa mikroskop yang tersedia berjumlah 25 buah banyak yang dalam kondisi berjamur dan hanya sekitar 7 buah mikroskop saja yang dapat digunakan. Adapun mikroskop yang digunakan merupakan mikroskop cahaya matahari, akan lebih baik apabila dilakukan peningkatan kualitas pada mikroskop yaitu menggunakan cahaya listrik. Mikroskop merupakan salah satu alat yang sangat diperlukan pada praktikum Biologi, maka dari itu siswa perlu mengetahui cara merawat mikroskop dengan baik seperti cara membawa mikroskop, membersihkan mikroskop setelah digunakan, dan lain-lain.

Kegiatan praktikum dapat dilaksanakan dengan baik apabila didukung dengan ketersediaan sarana yang diperlukan, tidak hanya kelengkapan tetapi juga kondisi sarana laboratorium juga perlu diperhatikan. Pada dasarnya, pengelolaan laboratorium merupakan tanggung jawab bersama baik pengelola maupun pengguna laboratorium. 
Oleh karena itu, setiap pihak yang terlibat harus memiliki kesadaran untuk mengatur, memelihara, laboratorium agar selalu dapat digunakan sebagaimana mestinya.

\section{KESIMPULAN}

Berdasarkan hasil deskripsi data dan pembahasan hasil penelitian, maka disimpulkan sebagai berikut:

1. Pelaksanaan praktikum yang mencakup minat siswa terhadap kegiatan laboratorium di SMA Negeri 1 Tebing Tinggi tergolong sangat baik, keadaan laboratorium yang tergolong baik, waktu praktikum tergolong baik, persiapan dan pelaksanaan praktikum tergolong baik, laporan dan evaluasi praktikum yang tergolong baik, dan kesehatan dan keselamatan kerja pada saat praktikum tergolong dalam kategori yang sangat baik, dan Frekuensi pelaksanaan praktikum Biologi selama semester genap di SMA Negeri 1 Tebing Tinggi masih tergolong kurang baik.

2. Kelengkapan sarana di laboratorium Biologi SMA Negeri 1 Tebing Tinggi sudah sangat baik, semua sarana, perlengkapan, alat dan bahan yang diperlukan yang sesuai dengan Permendiknas No. 24 Tahun 2007 telah tersedia. Kondisi sarana di laboratorium sebagian besar dalam kondisi baik.

3. Kendala yang dialami dalam pelaksanaan praktikum biologi di SMA Negeri 1 selama semester genap adalah kurangnya inisiatif guru dalam pemanfaatan sarana laboratorium yang telah tersedia dan banyak mikroskop yang dalam kondisi tidak baik sehingga tidak dapat digunakan.

\section{DAFTAR PUSTAKA}

Ariyati, E. (2010). Pembelajaran Berbasis Praktikum Untuk Meningkatkan Kemampuan Berpikir Kritis Mahasiswa. Jurnal Matematika dan IPA, 1(2),01-012.

Hamidah, A., Sari, N., dan Budianingsih, R. (2013). Manajemen Laboratorium Biologi Beberapa SMA Swasta di Kota Jambi. Jurnal Sainmatika, 7(1),01-010.

Lubis, S., dan Rizkia, D. (2017). Efektivitas Penggunaan Laboratorium Dalam Pembelajaran Biologi Kelas $X$ di SMA
Negeri 1 Unggul Baitussalam, Artikel, Universitas Abulyatama.

Mastika, N., Adnyana, I., dan Setiawan, A. (2014). Analisis Standarisasi Laboratorium Biologi dalam Proses Pembelajaran di SMA Negeri Kota Denpasar. Jurnal Penelitian Pascasarjana UNDIKSHA, 4(1),01-010.

Nasution, N., dan Hasairin, A. (2016). Analisis Sarana dan Pemanfaatan Laboratorium IPA (Biologi) dalam Pembelajaran Biologi Kelas XI di SMA Swasta Nusantara Lubuk Pakam. Jurnal Pelita Pendidikan, 4(4),031037.

Nazila, N. (2017). Analisis Pelaksanaan Praktikum Pada Pembelajaran Biologi Kelas X MAN Tanjungpinang Tahun Ajaran 2016/2017, Artikel, Universitas Maritim Raja Ali Haji.

Rezeqi, S. dan Hasruddin. (2012). Analisis Pelaksanaan Praktikum Biologi Dan Permasalahannya di SMA Negeri Sekabupaten Karo. Jurnal Tabularasa PPS UNIMED, 9(1): 017-032.

Tuysuz, Cengis. (2010). The Effect of the Virtual Laboratory on Student' Achievement and Attitude in Chemistry. IOJES, 2 (1), 037053.

Siburian, F., Sinambela, M., dan Septie. (2017). Analisis Pelaksanaan Praktikum pada Mata Pelajaran Biologi di Kelas X SMA Negeri 16 Medan. Jurnal Pelita Pendidikan, 5(2): 021031.

Sugiyono., (2017), Metode Penelitian Pendidikan Pendekatan Kuantitatif, Kualitatif, dan $R \& D$, Penerbit Alfabeta, Bandung. 